\title{
Del monólogo eurocéntrico a la enseñanza de la diferencia colonial: el debate žižek/mignolo
}

\author{
From the Eurocentric monologue to the teaching of the colonial difference: \\ The žižek / mignolo debate
}

Facundo Giuliano ${ }^{1}$

\section{Resumen}

Para quienes piensan que el eurocentrismo fue un problema "de moda" ya superado, este ensayo evidencia que no lo fue y que se trata de un asunto espinoso todavía abierto. En este sentido, las disecciones que componen estas páginas apuntan a reconstruir el debate entre dos de los pensadores más importantes de este tiempo. La metodología es hermenéutica desde la perspectiva crítica de este ensayo que, no sólo se nutre de leer con minucia los argumentos y contra-argumentos, sino también de haber interpelado a ambas posiciones desde diferentes movimientos de problematización. Podrán observarse las resonancias y profundizaciones de esos cruces, así como el desglose de sus gestualidades teóricas. En el monologar del eurocentrismo podrá notarse la persistencia en la universalización del legado europeo planteado como camino "único" a la re-politización, a la liberación o a la solución de los dilemas contemporáneos, lo que ha permitido en forma favorable la colonialidad y las estrategias de re-occidentalización. Por otro lado, la enseñanza de la diferencia colonial permite descreer de los caminos únicos o universales que prometen "el paraíso" a costa de sacrificar los legados (inter)culturales del resto del mundo no-europeo. Desde este movimiento, se postula una praxis descolonial del pensar que brega por la coexistencia de universales situados, no abstracta y desprovista de cualquier tiranía disciplinaria. Finalmente, queda insinuada la pregunta sobre la lucha por la coexistencia con un legado que niega o interrumpe los demás, al tiempo que se busca delinear formas de descolonización educativas que recuperen y reconstituyan las memorias colectivas.

Palabras clave: Walter Mignolo; educación descolonial; geopolíticas del conocimiento; re-occidentalización, colonialidad; Slavoj Žižek.

\section{Abstract:}

For those who think that Eurocentrism was a "fashionable" problem that has already been overcome, this essay shows that it was not and that it is a thorny issue that is still open. In this sense, the dissections that make up these pages aim to reconstruct

\footnotetext{
1 Doctor por la Facultad de Filosofía y Letras de la Universidad de Buenos Aires, Argentina. Pertenece al Consejo Nacional de Investigaciones Científicas y Técnicas (Argentina). Director del proyecto de investigación FiloCyT "Educación, filosofía y psicoanálisis: la potencia de un anudamiento indisciplinario frente al capitalismo contemporáneo" con sede en el Instituto de Investigaciones en Ciencias de la Educación (Universidad de Buenos Aires). Correo: giulianofacundo@gmail.com http://orcid.org/o000-0003-3404-1612
}

Recibido: 07/07/2020 - Aprobado: 09/10/2020

Giuliano, F. (2020). Del monólogo eurocéntrico a la enseñanza de la diferencia colonial: el debate žižek/mignolo. Ciencia E Interculturalidad, $27(02), 80$ - 93. https://doi.org/10.5377/rci.v27i02.10433 
the debate between two of the most important thinkers of this time. The methodology is hermeneutical from the critical perspective of this essay, which not only draws on carefully reading the arguments and counter-arguments, but also on having questioned both positions from different movements of problematization. The resonances and deepening of these crosses can be observed, as well as the breakdown of their theoretical gestures. In the monologue of Eurocentrism, the persistence in the universalization of the European legacy proposed as a "unique" path to re-politicization, liberation or the solution of contemporary dilemmas can be noted, which has favorably allowed coloniality and strategies of re-westernization. On the other hand, the teaching of the colonial difference allows disbelief in the unique or universal paths that promise "paradise" at the cost of sacrificing the intercultural legacies of the rest of the nonEuropean world. From this movement, a decolonial praxis of thinking is postulated that strives for the coexistence of situated universals, not abstract and devoid of any disciplinary tyranny. Finally, the question about the struggle for coexistence with a legacy that denies or interrupts others remains, while at the same time seeking to delineate forms of educational decolonization that recover and reconstitute collective memories.

Keywords: Walter Mignolo; decolonial education; geopolitics of knowledge; rewesternization; coloniality; Slavoj Žižek.

\section{Introducción}

\section{Puntapié inicial: eurocentrismo sí / eurocentrismo no}

Este ensayo podría confesarse portador de una de las más importantes discusiones filosóficas en lo que va del siglo XXI. Cualquier editorial podría fácilmente poner un título clamoroso y subtitularlo "El debate Žižek/Mignolo", como hace décadas se hizo con Chomsky y Foucault o, más recientemente, entre Badiou y Gauchet. Claro, generalmente el convite que da audiencia o buenas ventas suele involucrar a dos pesos pesados - mayormente hombres - con cierta diferencia en sus contenidos filosóficos, aunque curiosamente emparentados con los mismos términos de raigambre europea. De cualquier modo, la novedad aquí radicaría en que un importante pensador latinoamericano sería "contrincante" del llamado "filósofo más peligroso de occidente" y esto podría causar el morbo de la audiencia. Pero, afortunadamente, se ha optado por tomar otro camino diferente al del rating, el mainstream o los formatos a los que nos tienen habituados los medios masivos de comunicación y las redes sociales.

Desde hace algunos años, incluso décadas, estos pensadores tan disímiles vienen echando leña al fuego de la discusión y el tema de fondo que resuena es: eurocentrismo sí / eurocentrismo no. Y esto es precisamente lo que bifurca los caminos y hace que desde un lugar haya una serie de provocaciones, insultos, subestimaciones, generalizaciones u homogeneizaciones y del otro una suerte de enseñanza paciente desde 


\section{CIENCIAS SOCIALES}

una diferencia (y herida) colonial de la cual el europeo habla con sorna. En última instancia, lo que está en juego en este debate crucial del siglo XXI es nada menos que el proceso creciente de re-occidentalización (visto en la remodelación de las formas de pensamiento occidentales: cristianismo, liberalismo, marxismo, etc.) versus la des-occidentalización y la descolonialidad en todos los ámbitos del vivir, la política, la economía, la estética, las religiones, el conocimiento y la subjetividad.

\section{¿Re-occidentalización o colonialidad? ¡No, gracias!}

Hace casi dos décadas, Walter Mignolo (2001) alertaba sobre la geopolítica del conocimiento en la que se mueve Žižek con su alegato izquierdista frente a las críticas al eurocentrismo quien, cual Hobsbawm en su época y otros/as en la actualidad, intenta "recuperar la herencia fundamental de Europa" en su lado iluminado e ilustrado desatendiendo, por cierto, las atrocidades cometidas en su nombre. En este sentido, Mignolo ya señalaba cómo la Europa de Žižek que tantas veces ha decidido y hablado por el resto del planeta tiene una variada compañía para realizar los ideales de justicia y democracia que no son "fundamentalmente europeos" sino de la mayor parte de la gente del planeta. Por supuesto, este señalamiento era realizado sobre la base del antagonismo que Žižek (2001) marcaba entre universalismo y globalización insistiendo en el potencial de la politización democrática como el "verdadero legado europeo" desde los griegos hasta la actualidad y como "única repolitización" que podría "romper el círculo vicioso de la globalización liberal destinada a engendrar las más regresivas formas del odio fundamentalista" (p. 200).

El texto original de Žižek (2011a), publicado en 1998 (núm. 4, vol. 24 de la revista Critical Inquiry), fue retocado para re-publicarse al año siguiente como parte de su libro The Ticklish Subject (Verso, 1999) y donde paradójicamente sostiene que "el acontecimiento como retorno a las raíces sólo puede ser una apariencia que se adecua perfectamente al movimiento circular capitalista o, en el peor de los casos, lleva a catástrofes como el nazismo" (p. 228). Es interesante aquí cómo el propio argumento expuesto por Žižek se muerde la cola o se pisa los talones con lo anteriormente planteado, tal vez al modo de un auténtico acto fallido portador de cierta verdad ineludible. Pues si el "retorno a las raíces" se adecua perfectamente al movimiento circular capitalista o lleva a catástrofes como la mencionada (y podríamos señalar a la misma entre otras del siglo XX como un retorno de algo que comenzó mucho antes, digamos 1492 por convidar precisión, pero que curiosamente suele ser olvidado por los pensadores de catástrofes o de acontecimientos o de ciertas éticas que ven allí su "punto cero"), ¿por qué insiste Žižek en recuperar el "verdadero legado europeo" que va desde los griegos hasta la actualidad y sería este la única "repolitización" que podría romper dicho círculo vicioso? Žižek (2011a) mismo, opone globalización a universalismo por la particularización de la primera pero no ve -o no le interesa ver- la particularización de la segunda: 
Hoy en día, más que nunca, hay que insistir en que el único camino abierto a la emergencia de un acontecimiento es el que quiebra el círculo vicioso de la globalizacióncon-particularización, (re)afirmando la dimensión de la universalidad contra la globalización capitalista. (...) en consecuencia, hoy necesitamos un gesto que socave la globalización capitalista desde el punto de vista de la verdad universal, así como el cristianismo paulino socavó al imperio global romano. (p. 229).

Curiosa superposición de argumentos que pondera el retorno a las raíces griegas como única repolitización que supone estar exenta de particularización o "único camino abierto" a la emergencia de un acontecimiento directamente vinculado a la universalidad -o a la verdad universal-. No es para nada casual que Žižek encuentre la gestualidad adecuada al respecto en movimientos con pretensiones universalistas como el cristianismo y el marxismo. De hecho, en uno de sus últimos libros, Žižek (2018a) sostiene que "hoy en día la única manera de seguir siendo fiel a Marx ya no es ser "marxista», sino repetir el gesto fundacional de Marx de una manera nueva" (p. 76). ¿Será este también un notable caso de la famosa "compulsión a la repetición" de la que hablaba Freud y en la que el pensamiento europeo parece estar infatuado o, como mínimo, (gozosamente) implicado hace tantos siglos?

Así es como uno de los principales críticos de la política identitaria, termina por quedar preso de lo mismo y verificando el vínculo de la política de identidad (de raíz griega) con cierto fundamentalismo universalista posmoderno. Mignolo (2011) ha dejado claro que la diferencia colonial al tornarse ineludible reclama como vital para la ética, la política y la epistemología del presente reconocer que la totalidad de la epistemología occidental ha dejado de ser válida para todo el planeta, lo cual implica que "Grecia ya no puede ser el punto de referencia de las nuevas utopías y los nuevos puntos de llegada, tal como sostiene Žižek" (p. 61). Como puede observarse, casi una década más tarde, Mignolo (2011) revisa los argumentos actualizados de Žižek y encuentra que en su referencia a las "formas de odio fundamentalista" excluye al "legado europeo fundamental" como si fuese una excepción o quedase excluido de toda forma de "odio fundamentalista", reproduciendo la macro-narrativa de la civilización occidental (desde la Antigua Grecia hasta el Atlántico Norte) y prescindiendo de la macro-narrativa del mundo moderno-colonial en el que surgió el conflicto entre globalización y universalidad. ${ }^{2}$ Aquí sitúa Mignolo (2011) la omisión, por parte de

\footnotetext{
2 Y añade: "Aun decidiendo que las soluciones a los dilemas contemporáneos se pueden encontrar en la filosofía política y moral griega, es más difícil aceptar que ésta sea la única posibilidad, y por lo tanto, que le pertenece al legado de Grecia en la historia europea. El primer problema sería, entonces, diferenciar la contribución de Grecia a la civilización humana de la contribución europea desde el Renacimiento en adelante, desde los albores del mundo moderno-colonial. De ese modo, el mundo árabe-islámico podría reapropiarse el legado griego en la medida en que gran parte del pensamiento griego en la Europa cristiana pasó por las traducciones árabes. Por otra parte, algo similar podría decirse de otros legados -el chino, el indio, el del África subsahariana o el de los indios americanos, los criollos, los latinoamericanos y los caribeños- que no son parte del legado ni griego ni europeo (...), sino que son, más bien, legados propios que marcan constantemente rupturas y discontinuidades con la tradición clásica europea. Todos estos legados co-existieron y co-existen: no son cuestiones superadas, cuestiones del pasado, eclipsadas por la posibilidad única de la civilización occidental. A partir del siglo XXI es evidente que la historia del mundo que legó la Cristiandad Occidental y que secularizó Hegel, es simplemente insostenible" (Mignolo, 2011, pp. 67-68).
} 
Žižek, de la diferencia colonial que surge, en primer lugar, como consecuencia de la colonialidad del poder mediada por la colonialidad del saber, y que impone fronteras al pensamiento a excepción de que se trate de algún tipo de importación o exportación de la epistemología moderna -traducida en filosofía, ciencias naturales y/o socialesa lugares en los que dicho pensamiento no se considera posible. De este modo, la geopolítica del conocimiento planteada por Mignolo (2011) regionaliza el "legado europeo fundamental" situando el pensamiento en la diferencia colonial y creando las condiciones para dar lugar a otro pensamiento que no elude la planetarización del legado europeo, pero no se basa exclusivamente en él.

\section{Una vuelta de tuerca imposible a un problema ético-geopolítico abierto}

Luego de lo expuesto, el interesante e inesperado cruce más personal entre Žižek y Mignolo se daría unos años más tarde cuando el filósofo europeo Santiago Zabala publicara en Al Jazeera aquel escrito navideño de 2012 titulado "Slavoj Žižek y el rol del filósofo" (donde en un párrafo menciona conocidos nombres de filósofos y filósofas occidentales y termina optando por no mencionar "otros" de Brasil, China o Australia), al cual Dabashi respondería perspicazmente a las semanas por el mismo medio con la pregunta $¿$ Pueden pensar los no-europeos? (que luego, al profundizar sus argumentos, se transformaría en un libro) y donde Mignolo entra al debate con un contundente escrito afirmativo. En este contexto, convendría prestar atención a algunos datos que alimentan políticamente un poco más esta discusión candente y cuyas brazas seguirán ardiendo cada vez que arda una herida colonial.

El artículo de Mignolo en Al Jazeera (19/02/13) se publica justo unos días antes que Žižek realice su visita al Birbeck College de la Universidad de Londres, donde acostumbra a ir una o dos veces al año a responder a sus críticos mediante alguna conferencia o seminario que justifica el puesto que allí posee. Esto le dio a Žižek el tiempo justo de preparar una respuesta rápida al escrito de Mignolo que contenía algunas observaciones críticas sobre el rol del filósofo europeo y los límites de la filosofía continental, el comunismo como una opción entre otras (y no la única frente al capitalismo) y la no-universalidad de la relevancia de obras como las del esloveno. Por supuesto, esto parece haber molestado a Žižek de modo tal que su humor particular y verborragia lo posicionaron en un lugar más grosero del habitual, no sólo por el famoso "Fuck you" propiciado a Mignolo en medio de su respuesta sino también por la pregunta arrogante lanzada a la audiencia en medio de su conferencia -luego de presentar el debate comenzado por Zabala en Al Jazeera y que provocó, según sus palabras, "respuestas bellamente violentas" que lo acusaban predeciblemente de eurocéntrico-, y que decía: "Hay un tipo, creo que enseña en Duke, ¿ustedes lo conocen?" Ante la afirmativa de la audiencia y la mención del nombre de Walter Mignolo, vuelve a la carga: "Sí, ¿es realmente tan estúpido en la vida real como suena?"3 Sería interesante recordar aquí

3 El audio del desboque puede consultarse aquí: https://backdoorbroadcasting.net/2013/o2/slavoj-zizek-a-reply-to-my-critics/ (Minuto 42). 
lo que dice Kusch (2007) a propósito del insulto como "último recurso para modificar el mundo (...) cuando ya nos sentimos atrapados, casi como en una matriz" donde "ya nada somos al margen de la acción" (p. 75).

Desde luego, Mignolo no entró en este juego más propio de un programa de chimentos. La descarga de Žižek contra Mignolo se convertiría en un acápite más políticamente correcto y minucioso de su libro Trouble in Paradise (Penguin Books, 2014), al mismo tiempo que ese mismo año Mignolo sería invitado por Zed Books a prologar el mencionado libro de Dabashi (publicado en 2015) donde, entre otras cuestiones, realiza un análisis del exabrupto de Žižek y su posición en el marco más amplio del debate con la filosofía continental y el eurocentrismo. ${ }^{4}$

Ese mismo 2014, en una búsqueda rebelde para con los discursos educativos hegemónicos (más habitualmente asociados a las corporaciones pedagógicas, didácticas, psicológicas o sociológicas), comencé a indagar sobre la base del olvido que algunos de los grandes discursos críticos -de la filosofía o el pensamiento contemporáneo- y sus referentes suelen guardar respecto de la educación -como cuestión neurálgica de diferentes problemáticas sociales-, con ánimos de conversar sobre algunos entrecruzamientos habitualmente desatendidos por la lógica misma de las disciplinas y lo interdisciplinario. Transcurridos algunos encuentros, se fue consolidando la idea de hacer público un libro que contenga dichas conversaciones y explore cierta geopolítica del conocimiento filosófico-educativo. El entusiasmo me llevó a conversar con bastante gente más de quienes aparecieron finalmente en el volumen, así como también me permitió ver con mis propios ojos y sentir con mi propia piel la soberbia epistémica de ciertas figuras muy citadas en los ambientes apellidados "críticos", pero que no pueden salirse del libreto de lo ya dicho, lo ya pensado, por ellos o el canon al que responden, es decir, figuritas con las que no se puede conversar de otra cosa que aquello sobre lo cual han escrito o han leído en sus referentes. Interesantemente, esta no fue mi experiencia con Žižek ni con Mignolo, así como podría mencionar a otros/as cuyas conversaciones no han quedado en el recinto de lo privado y se han hecho públicas por diferentes medios. Ciertamente, dicha travesía estuvo atravesada por una fuerte pulsión descolonial que provocaba preguntar o plantear, incluso a referentes más asociados a la filosofía continental, qué mirada tenían respecto de ciertos problemas directamente vinculados a la colonialidad. Las respuestas, las reacciones o los silencios han sido de lo más interesante. En dicho marco, mi interrogación puntual a Žižek se dio en nuestra conversación a partir de vincular el llamado por él "entusiasmo pragmático", propio de sectores que reclaman una educación "más concreta" destinada a resolver "problemas concretos", con un tipo de racionalidad colonial-eurocéntrica e interpelarlo sobre el lugar que queda para los sujetos y su liberación frente a ello,

4 De todos estos textos se encuentran traducciones actualmente (Dabashi, 2018; Mignolo, 2018a; Žižek, 2016), aquí mencionamos las referencias originales solo a fines de respetar cierta cronología del debate. 


\section{CIENCIAS SOCIALES}

cuestión que también planteaba un vínculo con la propuesta/opción descolonial. Su respuesta fue tan explosiva como sincera:

¡Oh Dios mío! Aquí me encuentro con un problema otra vez, puesto que yo soy eurocéntrico. (...) No creo en absoluto que las ideas en contra del eurocentrismo sean un arma importante en la batalla emancipadora. Esto de, "la vuelta a una sabiduría indígena original" o parecido, para mí es una total basura. (...) Incluso algunos de mis amigos latinoamericanos me dicen que admiran la idea de Morales de que hay una sabiduría indígena holística que es mejor. ¿Qué es lo que quieren? ¿A los Incas que hacían sacrificios humanos? No conozco ninguna mitología de ninguna civilización pre-moderna que fuese mejor de alguna manera. (...) Creo que algunas partes del eurocentrismo hacen énfasis en la universalidad de manera que cualquier lucha en la que nos veamos envueltos se convierte en una lucha universal en potencia. No creo en las luchas por identidades particulares. (...) Todavía creo en el valor universal de la idea básica eurocéntrica de la modernidad. Estoy a favor de ella. Esto no significa que nosotros los europeos seamos más. Lo que significa, precisamente, es que nuestro entorno cultural es en última instancia algo indiferente. Mi entorno cultural no me determina. Por supuesto, la gente políticamente correcta dirá que esto es una forma de colonialismo porque el sujeto universal que se defiende es realmente eurocéntrico. Aun así, pienso que el universalismo europeo puede criticarse a sí mismo de manera efectiva. Es suficientemente autocrítico. (Žižek en Giuliano, 2017, pp. 122-126).

Nuevamente encontramos algo similar a lo señalado más arriba: la afirmación explícita de su eurocentrismo se torna algo incompatible con el descreimiento por las luchas de identidades particulares, ¿por qué la intensa insistencia en el eurocentrismo no sería a fin de cuentas una guerra por una identidad particular que pretende ser impuesta global o universalmente en detrimento de otras? Claro que no se trata de caer en una disputa identitaria sino, más bien, de no quedar -como ha sucedido históricamente- subordinados a ella. Pues se trata de la misma lógica que clasifica, compara engañosamente y jerarquiza, haciendo que unos tengan "pensamiento" y otros tengan "mitos", o que unos tengan "filosofía" y otros tengan "sabiduría" -lo que Mignolo (2018a) llama racismo epistémico-. Como si todo pensamiento milenario de cualquier civilización "pre-moderna" que no sea cristiana, griega u occidental pudiera reducirse a una mera mitología exótica. Entonces, ¿hasta qué punto el entorno cultural es en última instancia algo indiferente? ¿Cuáles son los límites del universalismo europeo y de la soberanía del sujeto eurocentrado que parece bastarse a sí mismo y ser "suficientemente autocrítico"? ¿Qué pasa con las partes del eurocentrismo que hacen énfasis en la universalidad de manera que no cualquier lucha se convierte en una "lucha universal en potencia"? Las "exclusiones originarias" sobre las que se funda 
todo universalismo ${ }^{5}$, ¿solo quedan como restos "tematizables", cuestionables, motivo de "(re)negociaciones" o "desplazamientos" que legitiman la brecha entre su propia forma y contenido? ¿Qué pensar no está condicionado por el lugar, es decir, por un contexto caracterizado por el roce de lo geográfico con lo cultural?

\section{¿Problemas en el paraíso? El infierno está encantador...}

Pocos meses antes de la publicación de Rebeliones éticas, ya había sido traducido y publicado en español el libro de Žižek (2016), donde dedica un importante pasaje a Mignolo retomando -solamente- su intervención en Al Jazeera y titulándolo "La herida del eurocentrismo". Allí comienza señalando que el énfasis en el anti-eurocentrismo y la imperiosa necesidad de salir de los confines del pensamiento occidental -que dio a luz a la modernización capitalista- sería un axioma que, según él, forma parte del a priori de la Izquierda actual y alerta sobre la posibilidad de que este sea parte del principal "obstáculo epistemológico" para la renovación de la izquierda. Renglón seguido, en relación al capitalismo global, hace énfasis en ser "especialmente cautos para no sucumbir al antieurocentrismo no reflexivo que a veces sirve de tapadera ideológica al rechazo de aquello por lo que vale la pena luchar del legado europeo" (Žižek, 2016, p. 2016) y ubica a Mignolo como "un caso ejemplar" de este anti-eurocentrismo no reflexivo. A continuación, realiza una extensa cita del texto de Mignolo publicado en Al Jazeera, donde puntúa sobre uno de sus llamados más fuertes a que como intelectuales descoloniales, si no filósofos, hay mejores cosas que hacer que enzarzarse en los debates de la filosofía europea. Žižek interpreta esta interpelación como un "grito de guerra" que dice "iOlvidad Europa!" pasando por alto la afirmación de Mignolo -en el mismo artículo- de que sí lee filosofía continental, pero no en busca de luces-guías para tratar cuestiones no-europeas, sino por simple interés en lo que "ellos" piensan, cuáles son "sus" preocupaciones o en qué están "ellos"... algo que raramente sucede en sentido inverso.

Žižek profundiza su argumento poniendo una extensa cita de Fanon en el medio y subrayando que la ironía estriba en que tal "grito de guerra" no sería válido para Fanon, que estudió extensa e intensamente a Hegel, el psicoanálisis, a Sartre e incluso a Lacan. Sobre la cita de Fanon utilizada por Žižek, Dabashi (2018) y Mignolo (2018b) realizarán análisis insoslayables. Interesa aquí ahora detenernos en desnudar un poco más algunos de los argumentos de Žižek que, ante el aviso de Mignolo sobre que la identificación de un problema no implica que haya una sola solución, remarca que tampoco existe una sola identificación del problema y encontramos una multitud de formulaciones acerca de cuál es el problema y qué lo provoca. Para Žižek, las diferentes

\footnotetext{
5 Žižek (2011b) mismo lo deja claro: «La universalidad pasa a ser "real” precisa y únicamente cuando vuelve tematizables las exclusiones sobre las cuales se funda, cuestionándolas continuamente, renegociándolas, desplazándolas, o sea, asumiendo la brecha entre su propia forma y su propio contenido, concibiéndose a sí misma como no consumada en su mismo concepto» (p. 110).

6 Disponible en: https://www.aljazeera.com/indepth/opinion/2013/02/20132672747320891.html
} 


\section{CIENCIAS SOCIALES}

identificaciones del problema forman una unidad dialéctica ${ }^{7}$ con las soluciones propuestas o, incluso, la identificación de un problema ya se formula desde el punto de vista de su solución presunta/imaginada. Razón por la cual sostiene acertadamente que "el comunismo no es tan solo una de las soluciones, sino, en primer lugar, una formulación singular del problema cuando aparece dentro del horizonte comunista" (Žižek, 2016, p. 196). Desde ahí critica la identificación del problema por parte de Mignolo, así como su formulación de la meta común compartida por todas las soluciones propuestas, encontrando universales abstractos o "recipientes vacíos que pueden significar muchas cosas incompatibles" en la enunciación de nociones como la de "armonía" o "plenitud de la vida". Žižek encuentra en la "sencilla" identificación entre desarrollo y muerte, así como en el rechazo de la guerra, la corrupción y el egoísmo, abstracciones no menos vacías. Indudablemente, el contenido de lo que entiende Mignolo por "armonía" y "plenitud de la vida" no podría zanjarse en ese artículo de prensa, lo cual no quita importancia a la observación de Žižek. Claramente, desde cosmologías indígenas y su potencial epistémico -que han sido arte y parte de diferentes voces del pensamiento latinoamericano-, tanto la idea de armonía como la de plenitud de la vida poseen contenidos y formas concretas que suelen resultar muy ajenas al pensamiento europeo. Por eso Žižek (2016) encuentra "abstracta" y "especialmente sospechosa" la oposición entre guerra y armonía, visualizándola como un llamado en contra de agravar los antagonismos sociales y en favor de una armonía pacífica del organismo social y sus desigualdades, ante lo cual prefiere con mucho ser llamado "fascista de izquierdas" e insistir en la dimensión emancipadora de la lucha.

Pero lejos de ello están la armonía y la plenitud de la vida a la que refiere Mignolo (2015) que, como se sabe, abraza la filosofía indígena (sin convertirla -ni convertirse- en una referencia exotizada) afincada en palabras claves como Suma qamaña en aymara o Sumak kawsay en quechua -que etimológicamente remiten a vivir en plenitud y armonía y que habitualmente se traducen como "vivir bien" o "buen vivir" (p. 90)-. La armonía del "buen vivir" está instalada en una genealogía de lucha, resistencia y re-existencia, que "es significativa, a principios del siglo XVII, cuando la formación del capitalismo mostraba ya un desprecio por vidas humanas desechables (indios y negros, fundamentalmente), sometidos a la explotación del trabajo, expropiados de su morada" (Mignolo, 2015, p. 274) -la tierra en la que estuvieron siendo y dejaron de estarlo para pasar a ser propiedad individual-, momento en que los europeos concentraron todos sus esfuerzos en el aumento de la producción sin importar quién muriera y arrasaron ideales como el del Sumak Kawsay que se liga(ba) a "la plenitud del vivir alcanzada a través del conocimiento" (Mignolo, 2015, p. 312) —atado espiritualmente a la tierra y sus recursos, tal como Waman Puma supo escribir-. De aquí que, lejos de

7 ¿Y si la identificación del problema formara cierta unidad analéctica con las diferentes soluciones planteadas? Así tal vez podría(n) considerar(se) aquellos problemas y soluciones que se sitúan más allá del horizonte de la totalidad e involucra a grupos oprimidos y pueblos que se sitúan como exterioridad y son capaces de lo imposible en tanto formas imprevisibles (para la totalidad) de identificar problemas y plantear soluciones. Esta sería una de las potencias descoloniales cuyo antecedente puede encontrarse también en Dussel (2011). 
lo que piensa Žižek (2016), lo que Mignolo ofrece no es una especie de "posmodernidad alternativa" traducida en "diferentes maneras de superar la modernidad europea (capitalista)" (p. 196), sino ampliar los lugares de enunciación considerando el suelo desde el cual parten los pensamientos para no caer, entre otras cosas, presos del legado europeo con sus pretensiones universalistas -que con tanta firmeza siente el deber de defender Žižek-. Más precisamente, una "posmodernidad alternativa" acarrearía una "pos-colonialidad alternativa" que implicaría una reorganización o reactualización de la colonialidad, a la vez que su propuesta no se plantea en términos de superación (consustancial al esquema de la modernidad/colonialidad) sino de coexistencia política y ética cambiando "los términos de la conversación, y no solo el contenido, dejando de buscar 'lo nuevo' que supera lo anterior, lo 'nuevo' que deja atrás 'la tradición', lo 'pasado', lo 'viejo'" (Mignolo, 2001, p. 30). No se trata de superación, sino de "ensanchamiento del espacio, de [re]emergencia de lugares de enunciación" que afirman "su propio derecho y necesidad a la [co]existencia" (Mignolo, 2001, p. 31).

\section{Salando las heridas: cicatrices abiertas e hirientes sonrientes}

En conclusión: No puede obviarse la postura de Žižek respecto de "la verdadera victoria sobre la colonización" y su reivindicación de la herida colonial. Para el europeo, "la verdadera victoria sobre la colonización no consiste en regresar a una existencia precolonial «auténtica», y mucho menos a ninguna «síntesis» entre la civilización moderna y los orígenes premodernos, sino, paradójicamente, en perder completamente esos orígenes premodernos" (Žižek, 2016, p. 197). Interesante orientación de la victoria viniendo de un pensador que no pierde sus "orígenes pre-modernos" y que sintoniza con la pérdida de herencia promovida por Sloterdijk (2014) para el resto del mundo.

¿Por qué el pensamiento europeo se afana de que el resto del mundo atravesado por su colonialidad pierda sus "orígenes pre-modernos"; mientras que para ellos sus propios orígenes forman parte del "legado europeo fundamental"? Invirtiendo y parafraseando un refrán popular: "Ante la ley dispareja, cualquiera se queja". Y ya son muchas las quejas. Frente a pensamientos como estos, algunas heridas vuelven abrirse o, directamente, nunca se cierran. Pero a este respecto Žižek (2016) alerta irónicamente sobre la gente que se toma demasiado en serio curar las heridas de los demás y se pregunta sobre el disfrute de la propia herida, señalando como una pesadilla curar la herida colonial (lo cual para él sí consistiría en regresar a ${ }^{8}$ la realidad precolonial).

8 En una entrevista reciente Žižek afirma: "Walter Mignolo se ha hecho relativamente famoso por defender la idea de que, si el capitalismo es malo, debemos volver, no al comunismo, sino a las viejas tradiciones locales, la antigua sabiduría de Latinoamérica, África, como una resistencia (...) Estoy en desacuerdo con esa idea de regresar a alguna sabiduría primordial." Disponible en: https://www. perfil.com/noticias/periodismopuro/zizek-trump-como-peron-mezcla-extremos.phtml Siempre fiel al legado moderno, la posición filosófica de Žižek se empecina en leer -en posiciones como las de Mignolo- retornos a épocas o tradiciones pasadas y prerrogativas identitarias-fundamentalistas que confunden -o imponen- los términos de la cuestión, al tiempo que ubica al comunismo como el único retorno posible frente al capitalismo. Por su parte, Mignolo (2018b) enseña que la "Re-surgencia al igual que la re-existencia no son propuestas para volver al pasado sino para definir proyectos en el presente que ya no son los presentes de los tres grandes relatos de la civilización occidental: teología cristiana y sus variantes, liberalismo y sus variantes, y marxismo y sus variantes" (p. 225). 


\section{CIENCIAS SOCIALES}

Aunque sepamos que la herida no se cura, que en el mejor de los casos se sana y que, a veces, necesitamos arrimar al fuego y hacer arder hasta la fundición la misma arma que nos hirió para comenzar algún proceso de sanación... Para pueblos que conviven atravesados por el significante de la desaparición, la tortura, el exterminio, la subclasificación, el menosprecio, la violencia patriarcal y el racismo occidental, esto es, la herida colonial, no será con la propia desintegración, negación o pérdida de las "formas tradicionales" que se abra algún espacio de liberación -como creen Žižek y tantos/as más-. La perspectiva dialéctica de Žižek (2016), fiel a Hegel, parece hacerle encontrar un "potencial liberador" en la herida, que no dice cuál es, aunque quizá pueda intuirse al leer un pasaje de un libro reciente:

El legado occidental, de hecho, no solo abarca la dominación imperialista (pos) colonial, sino también el examen crítico de la violencia y explotación que Occidente exportó al Tercer Mundo. Haití estuvo colonizado por los franceses, pero fue la Revolución Francesa lo que proporcionó el sustrato ideológico para la rebelión que liberó a los esclavos y fundó el Haití independiente; el proceso de descolonización se puso en marcha cuando las naciones colonizadas exigieron para ellas los mismos derechos que Occidente se había atribuido. En resumen, no deberíamos olvidar que Occidente es el que proporciona los mismos criterios mediante los cuales él y sus críticos observan su pasado criminal. Nos enfrentamos aquí con la dialéctica de la forma y el contenido: cuando los países coloniales exigen independencia y decretan el «regreso a las raíces», la propia forma de ese regreso (la de un Estado-nación independiente) es occidental. En su misma derrota (el hecho de perder las colonias), Occidente sigue ganando, pues impone al otro su forma social (Žižek, 2018b, p. 38).

Si el potencial liberador de la herida colonial radica en reivindicar aquello mismo que la causó y la re-abre o deja abierta, eso que parece liberación para algunos probablemente sea -o siga siendo- sufrimiento para otros. Por lo tanto, lo que está en juego evidentemente, como se ha advertido, es un fuerte proceso de re-occidentalización donde se considera que hasta el proceso de rebelión y descolonización de los haitianos se habría dado gracias a occidente ${ }^{9}$, donde occidente es el que proporciona los criterios mediante los cuales él se mira y lo mirarían sus críticos, donde no habría ningún tipo de exterioridad a occidente ya que todo fue concebido por él (hasta el mismísimo oriente). Habría que oponer una analéctica de forma y contenido al relato de Žižek, ya que cuando las colonias se independizaron nunca hubo tal "regreso a las raíces”, por el mismo motivo que él indica, pero más precisamente por la instalación

9 Frente a este planteo, Mignolo aclara: "Se dice que la revolución haitiana se debió a la influencia de la revolución francesa. Esa es la versión moderna, eurocéntrica. Lo que los revolucionarios haitianos hicieron fue 'aprovecharse' de la coyuntura política de la revolución francesa. Es totalmente eurocéntrico pensar que los esclavizados africanos se dieron cuenta que eran esclavos y que podían emanciparse porque ¡lo hicieron los franceses! Los esclavizados africanos sabían desde el momento en que los capturan en África que su destino era liberarse. Pero como no disponían del caudal económico del que dispuso la etno-clase burguesa para lanzarse contra el clero y la monarquía, sus esfuerzos emancipadores se redujeron al marronaje; y en el caso de los Pueblos Originarios o movimientos como el Taki Onkoy en el siglo XVI y las rebeliones de Tupac Katari y Tupac Amaru, ambos fueron anteriores a la revolución francesa" (en Giuliano, 2017, p. 145). 
de la colonialidad mediante todo tipo de instituciones inherentes a la modernidad, el establecimiento de lenguas hegemónicas, la consolidación de grupos internos colaboracionistas e importadores de técnicas, saberes e informaciones. No hubo -ni puede haber- vuelta atrás luego de la colonización y la instalación de la colonialidad del poder.

Dejaremos abierto entonces este acápite, invocando a Fanon (1965) por señalar un comienzo del horizonte de desprendimiento que nos interesa:

Entonces, hermanos, ¿cómo no comprender que tenemos algo mejor que hacer que seguir a esa Europa? Esa Europa que nunca ha dejado de hablar del hombre, que nunca ha dejado de proclamar que sólo le importaba el hombre, ahora sabemos qué sufrimientos ha pagado la humanidad con cada una de las victorias de su espíritu. Compañeros, el juego europeo ha terminado definitivamente, hay que encontrar otra cosa. Podemos hacer lo que nos plazca a condición de no imitar a Europa, a condición de no dejarnos obsesionar por el deseo de alcanzar a Europa (p. 159).

\section{Conclusiones}

\section{Último round en el ring de la coexistencia: legado emancipador europeo versus praxis descolonial del pensar}

¿Qué se manifiesta cuando Žižek (2018b) plantea que "el legado emancipador europeo no se puede reducir a "valores europeos»" (p. 39)?

Puede tratarse de un mero rechazo a la praxis descolonial del pensar, es decir, al desprendimiento de la tiranía de los universales abstractos y sus conceptos o disciplinas, que "reduce los universales y sus lugares de gestación a su propio lugar" (Mignolo, 2018b, p. 212). De este modo, puede verse que el cristianismo, el marxismo y el liberalismo comparten el universalismo eurocéntrico, aunque estos dos últimos sean vástagos seculares de la ilustración y rechacen al cristianismo (lo cual no quita que puedan convivir o compatibilizarse en ciertos pensamientos que conjugan marxismo y cristianismo o liberalismo y cristianismo). Por eso Žižek (2018b) y otros anti-decoloniales pos-marxistas atacan a Mignolo ${ }^{10} \mathrm{y}$ a otros defensores de la descolonialidad: no rechazan la (acertada) idea de que el comunismo es europeo, pero sí a toda propuesta que tenga como fuente de resistencia al capitalismo global algunas tradiciones asiáticas, latinoamericanas o africanas.

\footnotetext{
10 Si bien Mignolo (2018b) no intenta dar una respuesta puntual, logra poner de relieve que los distintos puntos de partida (los propios, los de Žižek y los de toda la esfera de la ciencia), como todo principio argumentativo, son emocionales y sobre esta base "irracional", aunque se construyan enormes y sofisticados edificios racionales, se trama la "verdad". Así, 'la verdad' no estaría en semejantes estructuras de argumentación, sino en los pre-supuestos o cimientos que las sostienen: vitalidad de la enseñanza náhuatl según la cual 'la verdad' se establece por el suelo que la sostiene y no por mera coherencia o correspondencia, pues afinca en el corazón y por eso se la 'siente' más que se la 'conoce'.
} 


\section{CIENCIAS SOCIALES}

Este debate filosófico/educativo enseña que la colonialidad del saber modela la subjetividad "tanto de quienes se sienten trabajando para la Secretaría Global del Conocimiento, como de quienes han sentido, y tal vez aun sientan, que deberían ser reconocidos por esa Secretaría" (Mignolo, 2018a, pp. 148-149), Mientras quienes se encuentran por fuera de esos dos casos parecen no existir como seres humanos pensantes o sólo los reportan como "objetos de estudio". Al mismo tiempo, algunos esfuerzos nos quedan por hacer a la gente no interesada en juntar flores del jardín de la filosofía europea ni en tolerar sus cercos: deshacernos (colectivamente) de las marcas inconscientes del eurocentrismo que recorre -y reactualiza- la historia de la colonialidad en sus distintas e interrelacionadas esferas.

Los ejemplos ofrecidos por Mignolo (2018a) sobre cómo "el eurocentrismo funciona en el inconsciente" (p. 134), de manera que llega a naturalizarse "el mundo visto, descripto y mapeado desde las perspectivas e intereses europeos" (p. 122), constituyen un interesante punto de partida en una contra-ofensiva que considere desembarazar y descolonizar al inconsciente de ese yugo. En este proceso, se incluye también el reclamo o alegato por las memorias ancestrales "cuyos legados fueron interrumpidos, en todo el planeta, por la corta victoria del eurocentrismo" (Mignolo, 2018b, p. 209). Erosionar esta interrupción depende de una transmisión, como lucha educativa, que recupere, restituya o reconstituya los fragmentos singulares del suelo comunal como memorias colectivas que liberan al tiempo y que dan qué sentir, qué pensar, qué conversar. Un entramar como lucha contra el silenciamiento, pero también como complicidad tejida y tendida entre generaciones.

\section{Agradecimiento}

Esta publicación obtuvo el financiamiento de: El Fondo de Asistencia Internacional de los Estudiantes y Académicos Noruegos (SAIH).

\section{Lista de referencias}

Dabashi, H. (2018). ¿Pueden pensar los no-europeos? En Facundo Giuliano (Comp.) ¿Podemos pensar los no-europeos? Ética decolonial y geopolíticas del conocer (69-120). Buenos Aires: del Signo.

Dussel, E. (2011). Filosofía de la liberación. México: Fondo de Cultura Económica.

Fanon, F. (1965). Los condenados de la tierra. México: Fondo de Cultura Económica.

Giuliano, F. (2017). Rebeliones éticas, palabras comunes. Conversaciones (filosóficas, politicas, educativas) con Judith Butler, Raúl Fornet-Betancourt, Walter Mignolo, Jacques Rancière, Slavoj Žižek. Buenos Aires: Miño y Dávila. 
Kusch, R. (2007). Obras completas: v. 3. Rosario: Fundación Ross.

Mignolo, W. (2001). Introducción. En Walter Mignolo (Comp.) Capitalismo y geopolítica del conocimiento. El eurocentrismo y la filosofía de la liberación el debate intelectual contemporáneo (9-53). Buenos Aires: del Signo.

Mignolo, W. (2011). El vuelco de la razón. Diferencia colonial y pensamiento fronterizo. Buenos Aires: del Signo.

Mignolo, W. (2015). Habitar la frontera. Sentir y pensar la descolonialidad (antología 1999-2014). Barcelona: Bellaterra.

Mignolo, W. (2018a). Sí, podemos. En Facundo Giuliano (Comp.) ¿Podemos pensar los no-europeos? Ética decolonial y geopolíticas del conocer (121-159). Buenos Aires: del Signo.

Mignolo, W. (2018b). Filosofía y diferencia epistémica colonial. En Facundo Giuliano (Comp.) ¿Podemos pensar los no-europeos? Ética decolonial y geopolíticas del conocer (203-229). Buenos Aires: del Signo.

Sloterdijk, P. (2014). Los hijos terribles de la Edad Moderna: sobre el experimento antigenealógico de la modernidad. Madrid: Siruela.

Žižek, S. (2001). Un alegato izquierdista por el eurocentrismo. En Walter Mignolo (Comp.) Capitalismo y geopolítica del conocimiento. El eurocentrismo y la filosofía de la liberación el debate intelectual contemporáneo (173-200). Buenos Aires: del Signo

Žižek, S. (2011a) El espinoso sujeto: el centro ausente de la ontología política. Buenos Aires: Paidós, 2011.

Žižek, S. (2011b) ¿Lucha de clases o posmodernismo? ¡Sí, por favor! En Judith Butler, Ernesto Laclau y Slavoj Žižek. Contingencia, hegemonía, universalidad. Diálogos contemporáneos en la izquierda (95-139). Buenos Aires: Fondo de Cultura Económica.

Žižek, S. (2016). Problemas en el paraíso. Del fin de la historia al fin del capitalismo. Barcelona: Anagrama.

Žižek, S. (2018a). La vigencia de El Manifiesto Comunista. Barcelona: Anagrama, 2018.

Žižek, S. (2018b). El coraje de la desesperanza. Crónicas del año en que actuamos peligrosamente. Barcelona: Anagrama. 